\title{
A importância da comunicação científica para a visibilidade de temáticas sociais: LGBT e Biblioteca Pública
}

\author{
The importance of scientific communication for the visibility of social themes: \\ LGBT and Public Library \\ Silvania Alves Ferreira \\ Doutoranda em Gestão e Organização do Conhecimento \\ Universidade Federal de Minas Gerais \\ silvanireis@gmail.com \\ Azilton Ferreira Viana \\ Doutorando em Memória Social, Patrimônio e Produção do Conhecimento \\ Universidade Federal de Minas Gerais \\ aziltonfviana@gmail.com \\ Dalgiza Andrade Oliveira \\ Doutora em Ciência da Informação \\ Universidade Federal de Minas Gerais \\ dalandrade@yahoo.com.br
}

\section{Resumo}

Este artigo discorre sobre a comunicação científica, por meio da produção científica, de sua contribuição para o desenvolvimento de pesquisas, para a ampliação do conhecimento e dos campos do saber que constituem a ciência. Analisa, por intermédio de duas pesquisas de mestrado, a produção científica sobre as temáticas Lésbicas, Gays, Bissexuais, Travestis e Transexuais (LGBT) e Biblioteca Pública, respectivamente, no intuito de responder à seguinte pergunta: como essas temáticas estão inseridas nas agendas de pesquisa dos Programas de Pós-Graduação (PPG) no Brasil? Trata-se de pesquisa de abordagem quantitativa. Foi empregado o método bibliométrico baseado no indicador de produção científica/número de trabalhos. Identificaram-se os programas de pós-graduação que produziram pesquisas sobre as temáticas; mapearam-se e quantificaram-se as teses e dissertações; verificou-se o número de produção em cada um dos PPG, a fim de perceber as áreas e os programas que mais se dedicaram às temáticas; analisou-se a distribuição temporal das temáticas entre os PPG; elencaram-se os principais termos utilizados nas teses e dissertações empregados para tratar as temáticas. Recuperaram-se 45 teses e dissertações sobre a temática LGBT no período de 2000 a 2016 e 88 pesquisas sobre Biblioteca Pública no período de 1970 a 2015. Pode-se afirmar que as duas temáticas se encontram inseridas nas agendas de pesquisa dos PPG.

\section{Palavras-Chave}

Comunicação científica. Segmento LGBT. Biblioteca pública. Programas de Pós-Graduação. Bibliometria.

\section{Abstract}

This article discusses scientific communication, through scientific production, its contribution to the development of research, to the expansion of knowledge and the fields of knowledge that constitute science. Analyzes, through two master's researches, the scientific production on the themes Lesbians, Gays, Bisexuals, Transvestites and Transsexuals (LGBT) and public library, respectively, in order to 
answer the following question: how these themes are inserted in the agendas of research of Graduate Programs in Brazil? This is a research with a quantitative approach. The bibliometric method based on the scientific production indicator/number of papers was used. The graduate programs that produced research on the themes were identified; theses and dissertations were mapped and quantified; the number of production in each of the PPGs was verified, in order to understand the areas and programs that were most dedicated to the themes; the temporal distribution of the themes among the PPG was analyzed; the main terms used in the theses and dissertations used to address the themes were listed. 45 theses and dissertations on the LGBT theme from 2000 to 2016 and 88 research on public library from 1970 to 2015 were recovered. It can be said that the two themes are included in the research agendas of the PPG.

\section{Keywords}

Scientific communication. LGBT segment. Public Library. Graduate Programs. Bibliometrics.

\section{INTRODUÇÃO}

É consenso entre diferentes áreas e campos do saber que o progresso da ciência somente é possível graças às contribuições de pesquisas realizadas que trazem novos dados e informações como também colaboram para a consolidação de conhecimentos já desenvolvidos em diferentes períodos históricos. Quando um pesquisador consulta uma publicação científica e encontra algo que já foi escrito sobre o assunto de seu interesse, ele tem condição de saber o que um autor pensava naquela época e como ele poderá refletir e prosseguir a partir de então (ZIMAN, 1979). Essa é uma das razões para se comunicar a ciência.

Nesse sentido, os resultados obtidos a partir de investigações científicas podem contribuir para o desenvolvimento das diversas áreas do conhecimento e a disseminação dos resultados de pesquisas, por meio de canais de disseminação (MUELLER, 2012), tais como revistas, periódicos científicos, teses e dissertações, é imprescindível para alcançar esse objetivo.

Há que se destacar que a Ciência da Informação concentra os estudos que são concernentes aos fenômenos que permeiam a informação nos seus aspectos de produção, seleção, aquisição, tratamento e transferência, dentre outros. Assim, entende-se como pertinente que abrigue reflexões também sobre temáticas relevantes para os processos que envolvem a sociedade. Daí a ênfase em dois trabalhos, resultantes de pesquisa de mestrado ${ }^{1}$, descritos mais abaixo.

Os processos de produção, disseminação e uso da informação, que compõem a estrutura da comunicação científica, encontram-se no rol de interesses de estudo da Ciência da Informação. O foco aqui será dado à etapa da produção.

O presente artigo analisa, por intermédio de duas pesquisas de mestrado, a produção científica sobre as temáticas Lésbicas, Gays, Bissexuais, Travestis e Transexuais (LGBT) e Biblioteca Pública, respectivamente, no intuito de responder à seguinte pergunta: como essas temáticas estão inseridas nas agendas de pesquisa dos Programas de Pós-Graduação no Brasil (PPG)?

\footnotetext{
${ }^{1}$ FERREIRA, S. A. Produção Científica sobre Biblioteca Pública nos Programas de Pós-Graduação em Ciência da Informação no Brasil. 2017. 164 f. Dissertação (Mestrado em Ciência da Informação) - Escola de Ciência da Informação, Universidade Federal de Minas Gerais. Belo Horizonte, 2017 e VIANA, A. F. A produção científica acerca da temática LGBT: um estudo propedêutico nas teses e dissertações na UFMG. 2017. 145 f. Dissertação (Mestrado em Ciência da Informação) - Escola de Ciência da Informação, Universidade Federal de Minas Gerais. Belo Horizonte, 2017. Ambos foram desenvolvidos no Programa de Pós-Graduação em Ciência da Informação (PPGCI) da Universidade Federal de Minas Gerais (UFMG), sob a orientação da Professora Dalgiza Andrade Oliveira.
} 
Nas pesquisas que subsidiam este estudo, identificaram-se os programas de pósgraduação que produziram pesquisas sobre as temáticas; mapearam-se e quantificaram-se as teses e dissertações; verificou-se o número de produção em cada um dos PPG, a fim de perceber as áreas e os programas que mais se dedicaram às temáticas; analisou-se a distribuição temporal das temáticas entre os PPG; elencaram-se os principais termos utilizados, nas teses e dissertações, empregados para tratar as temáticas.

\section{COMUNICAÇÃO CIENTÍFICA E A CONSOLIDAÇÃO DA CIÊNCIA}

Compreender como a comunicação científica se constituiu ao longo do tempo como elemento basilar para o desenvolvimento das diferentes áreas possibilita constatar que, à medida que a ciência avançou, promoveu-se impacto em diferentes áreas do conhecimento que modificaram as relações humanas. Essa nova realidade social, na acepção de Robredo (2012), foi possível graças a uma mudança paradigmática, iniciada pela filosofia, que se estendeu para todos os campos investigativos, num processo de transição iniciado no final da Idade Média.

As mudanças estabelecidas pelas diferentes correntes filosóficas, conforme indicado pelo autor, trouxeram algumas contribuições para melhor compreensão do processo de conhecimento cujo resultado da atividade científica deve traduzir e demonstrar os avanços, as conquistas, os melhoramentos, os desafios, os problemas, as correções, enfim todas as etapas do processo de desenvolvimento humano, no qual a ciência é sua máxima expressão.

As considerações, análises e reflexões realizadas apontam para a importância da consolidação de campos do conhecimento formalizados em seu aspecto humano na formação de pesquisadores e profissionais que são responsáveis pela comunicação científica.

Pesquisas científicas são essenciais para o desenvolvimento de uma área de estudo. Por meio de observações, da construção e experimentação de teorias e hipóteses, é possível gerar conhecimentos que contribuam para a evolução da ciência. O fazer científico requer o resgate do que já foi produzido pelos pares na área de estudo em questão. Por isso mesmo, a ciência é compreendida como um ato coletivo no qual as partes são construídas pelos pesquisadores a partir dos alicerces já estabelecidos pelos seus predecessores, conferindo-lhe sua natureza pública (ZIMAN, 1981).

Para que o conhecimento contribua para a evolução da ciência, é preciso que ele seja comunicado, visto que, ao comunicar o resultado de uma pesquisa, esta deixa de fazer parte do plano individual e torna-se parte do acervo do conhecimento público (ZIMAN, 1979).

Se os resultados de uma pesquisa não são avaliados pelos pares e publicados em veículos aceitos como legítimos pela área em questão, não são considerados como conhecimento científico e, sem publicação, não há certificação (MUELLER, 2012).

Segundo Meadows (1999, p. vii), "A comunicação situa-se no próprio coração da ciência. [...] Qualquer que seja o ângulo pelo qual a examinemos, a comunicação eficiente e eficaz constitui parte essencial do processo de investigação científica.". Cumpre destacar aqui que o conceito de comunicação científica foi "[...] proposto por John Bernal, no final dos anos trinta, para designar o processo específico de produção, consumo e transferência de informação no campo científico [...]" (CUNHA; CAVALCANTI, 2008, p. 97). Garvey (1979, p. xi, tradução nossa) já antecipava, em sua obra Comunication: the essence of science, a comunicação científica como:

[...] todo o espectro das atividades associadas com a produção, disseminação e uso da informação, desde o momento em que o cientista tem a ideia para sua pesquisa 
até que a informação sobre os resultados de sua pesquisa seja aceita como um componente de conhecimento científico.

Entende-se que o processo da comunicação científica implica uma interação entre os cientistas que trocam informações por meio de encontros científicos, relatórios técnicos, livros e artigos de periódicos científicos, dentre outros, com o intuito de buscar informações e/ou divulgar os resultados de suas pesquisas, que também serão usadas por outros cientistas. Assim, nas palavras de Weitzel (2006, p. 98), o "[...] cientista exerce, ao mesmo tempo, o papel de produtor, distribuidor e consumidor de informação científica [...]", funcionando como um ciclo.

Duas dimensões em relação à comunicação científica são apontadas por Christovão (1979). A primeira que se estabelece é aquela considerada como ciência "filtrada" 2 para a sociedade e a segunda, para os pesquisadores, na qual se volta para si mesma. Há, contudo, dificuldades na tentativa de estabelecer limites definidos entre o que é pertencente à comunicação formal e o que é de responsabilidade da comunicação informal.

Na concepção da autora, o sistema de comunicação informal utiliza-se de conversas, contatos interpessoais, telefonemas, cartas trocadas entre cientistas, visitas interinstitucionais, reuniões científicas (congressos nacionais e internacionais, reuniões de grupos locais), etc. Já o sistema de comunicação formal, de acordo com Mueller (2012, p. 130), "[...] incluía os artigos publicados em revistas científicas, a edição de livros, teses e dissertações e trabaIhos publicados em anais de grandes reuniões científicas, entre outros.".

Para fins dos estudos que serão relatados a seguir, optou-se por utilizar as teses e dissertações, frutos de pesquisas nos cursos de pós-graduação stricto sensu, com o objetivo de conferir reconhecimento de seus pares aos resultados apresentados pelo pesquisador. Esses documentos vinculam-se à qualificação do investigador na opção do grau de mestre ou doutor (CAMPELLO, 2007).

\section{PRODUÇÃO CIENTÍFICA}

Para haver comunicação científica, pressupõe-se a existência das atividades mencionadas por Garvey (1979), sendo uma delas a produção científica, que foi definida por Lourenço $(1997$, p. 25-26) como "[...] toda produção documental, independente do suporte [...] sobre um determinado assunto de interesse de uma comunidade científica específica, que contribua para o desenvolvimento da ciência e para a abertura de novos horizontes de pesquias.". Corroborando essa definição, Pizzani, Martinez e Hayashi (2013, p. 171) explicam que "A produção científica pode ser representada pelo conjunto de trabalhos produzidos pelos pesquisadores da área que atuam em programas de pós-graduação.". Num desígnio mais ampliado, Witter (1996, p. 8) a conceitua como "[...] a forma pela qual a universidade ou instituição de pesquisa se faz presente no saber-fazer-poder-ciência [...]".

Percebe-se, nas definições apresentadas, que a produção científica e o desenvolvimento científico estão fortemente vinculados e que as universidades, por meio dos seus programas de pós-graduação, destacam-se como protagonistas nesse processo, pois aparecem como importantes instituições produtoras de ciência uma vez que são responsáveis pela formação de pesquisadores.

\footnotetext{
2 o termo "filtrada" aqui empregado foi o mesmo utilizado por Christovão (1979), que significa um processo que atua na ciência à semelhança do que ocorre com filtros de água. Ao contrário de autores e/ou editores efetuarem um processo de seleção linear, a própria estrutura da ciência se encarrega de filtrar.
} 
Nesse sentido, estudos de produção científica assumem papel relevante para a implementação de políticas para desenvolvimento científico e tecnológico, para compreensão da evolução de campos de estudos, para medir produção de pesquisadores, instituições ou de países, tendo em vista que a produção científica é considerada como "[...] a base para o desenvolvimento e a superação da dependência entre países e entre regiões de um mesmo país; é o veículo para a melhoria da qualidade de vida dos habitantes de um país [...]." (WITTER, 1996, p. 8).

Para analisar a produção científica, é necessária a utilização de medidas conhecidas como indicadores, definidos por Santos e Kobashi (2005, on-line) como:

[...] dados estatísticos usados para avaliar as potencialidades da base científica e tecnológica dos países, monitorar as oportunidades em diferentes áreas e identificar atividades e projetos mais promissores para o futuro, de modo a auxiliar as decisões estratégicas dos gestores da política científica e tecnológica e também para que a comunidade científica conheça o sistema no qual está inserida.

Dentre os indicadores quantitativos mais conhecidos estão aqueles categorizados como: 1) de citações: usado para fazer a contagem do número de citações recebidas por uma publicação; 2) de ligação/coautoria: utilizado para medir o grau de colaboração na ciência e 3) produção científica/número de trabalho. Para subsidiar, metodologicamente, as investigações que originaram este estudo, foi empregado o método bibliométrico com base no indicador de produção científica/número de trabalho. Com esse tipo de indicador, MaciasChapula (1998), Santos e Kobashi (2005) explicam que é possível fazer a contagem do número de publicações por tipo de documento, por instituições, área do conhecimento, país, etc. Além disso, a dinâmica da pesquisa em um determinado país pode ser monitorada e sua tendência traçada ao longo do tempo.

\section{BIBLIOMETRIA COMO FERRAMENTA METODOLÓGICA}

A segunda metade do século XX foi marcada pelo aumento exponencial da produção e consumo de informação, que caracterizou a explosão bibliográfica. Esse fenômeno informacional passou a ser tema central nas discussões em várias áreas do conhecimento, principalmente naquelas que se relacionam diretamente com a produção e comunicação científica, tais como a Biblioteconomia e a Ciência da Informação (SOUZA; OLIVEIRA, 2007).

Pesquisadores dessas duas áreas utilizam-se muito de técnicas de medição para investigar o comportamento da informação e uma delas é a Bibliometria, considerada por Vanti (2002) como "subcampo" ou "subdisciplina" da Ciência da Informação.

Para Tague-Sutcliffe (1992 apud MACIAS-CHAPULA, 1998), a Bibliometria estuda os aspectos quantitativos da produção, disseminação e uso da informação registrada; desenvolve padrões e modelos matemáticos para medir esses processos e usa seus resultados para fazer previsões e apoiar tomadas de decisão.

Nesse sentido, os resultados alcançados com mensurações ou quantificações revelam aspectos muito além do que números, tendo em vista que "[...] ao mesmo tempo que os estudos bibliométricos se dedicam a alguns elementos que definem um fator de impacto, possibilitam também a definição de uma série de indícios característicos da produção científica estudada [...]" (SOUZA; OLIVEIRA, 2007, p. 76).

A constatação realizada pelos autores revela um deslocamento da preocupação de pesquisadores e cientistas em relação à qualidade tanto da produção científica quanto com 
o desenvolvimento de metodologias para pesquisar a prática e os indicadores dessa produção, no ensejo de sustentar o incremento de políticas científicas nos diferentes domínios do saber.

Nessa perspectiva, os estudos bibliométricos constituem-se como importante recurso para conferir o estado da arte de uma dada área do conhecimento, revelar frentes de pesquisa, núcleo central de periódicos, elite de pesquisadores, ranking de produtividade de instituições, tendências e emergência de temáticas, dentre outros.

\section{METODOLOGIA}

Os dois estudos, cujos resultados são apresentados na sequência, utilizaram-se da Bibliometria como técnica para analisar a produção científica sobre as temáticas LGBT e Biblioteca Pública. Cada um deles teve o corpus, período e universo diferentes.

Na temática LGBT, o estudo caracterizou-se como bibliográfico, exploratório de abordagem quantitativa. $O$ universo constituiu-se dos PPG da UFMG, a partir das teses e dissertações depositadas na Biblioteca Digital de Teses e Dissertações (BDTD) dessa instituição. 0 recorte temporal foi o período de 2000 a 2016.

A busca foi realizada no período de 1 o de maio a 31 de julho de 2016, a partir de 16 palavras-chave nos campos título, resumo, palavras-chave, a saber: homossexual, lésbica, LGBT, gay, travesti, bissexual, homossexualidade, homofobia, violência, preconceito, transexual, cidadania, terceiro gênero, transmasculinidades, bissexualismo e intersexualidade ${ }^{3}$.

Já na temática Biblioteca Pública, o estudo caracterizou-se como bibliográfico, descritivo de abordagens quantitativa e qualitativa. Entretanto, para o presente artigo, o foco será dado à parte da análise quantitativa. O recorte temporal compreendeu o período de 1970 a 2015 e o universo constituiu-se das teses e dissertações de 13 Programas de Pós-Graduação em Ciência da Informação (PPGCl), recomendados e reconhecidos pela Coordenação de Aperfeiçoamento de Pessoal de Nível Superior (Capes), nas seguintes Instituições de Ensino Superior (IES): Universidade Federal do Rio de Janeiro (UFRJ); Universidade de São Paulo (USP); Universidade Federal de Minas Gerais (UFMG); Universidade Federal da Paraíba (UFPB); Universidade de Brasília (UnB); Universidade Estadual Paulista Júlio de Mesquita Filho (UNESP); Universidade Federal da Bahia (UFBA); Universidade Federal de Santa Catarina (UFSC); Universidade Federal Fluminense (UFF); Universidade Federal de Pernambuco (UFPE); Universidade Estadual de Londrina (UEL); Universidade Federal do Estado do Rio de Janeiro (UNIRIO) e Universidade do Estado de Santa Catarina (UDESC).

A busca foi realizada no período de 10 de junho a 28 de agosto de 2016 nas Bibliotecas Digitais de Teses e Dissertações e nas páginas on-line dos PPGCl das universidades citadas; nos catálogos on-line das bibliotecas dessas universidades e no catálogo impresso de dissertações da UFPB ${ }^{4}$.

\footnotetext{
${ }^{3} \mathrm{~A}$ análise inicial das primeiras seis palavras-chave sobre a temática LGBT escolhidas foram vinculadas à identidade de gênero. A ampliação foi necessária no intuito de permitir a recuperação de produção científica que tratasse da temática LGBT sem associação às questões de identidade de gênero ou orientação sexual.

${ }^{4}$ Obra organizada pela Professora Maria Elizabeth Baltar Carneiro Albuquerque/UFPB. Destaca-se que, na época da realização dessa pesquisa de mestrado, defendida no PPGCI/UFMG, muitas teses e dissertações da UFPB ainda não estavam no meio digital e suas referências constavam nesse catálogo.
} 


\section{RESULTADOS ALCANÇADOS}

Os resultados que serão apresentados nesta seção constituem-se em um recorte dos dados quantitativos das pesquisas sobre a temática LGBT e Biblioteca Pública. Será dividida em subseções para apresentar os resultados de cada investigação.

\subsection{Evidenciações da temática LGBT}

Ao analisar as recuperações de documentos ${ }^{5}$, foi identificada a produção dos PPG a partir das palavras-chave, com a utilização de termos e nomenclaturas em uso por parte do segmento LGBT, a continuidade dos estudos referentes à temática, a temporalidade dos documentos e sua relevância para a construção do campo da Ciência da Informação.

Recuperaram-se 1756 documentos entre teses e dissertações na BDTD da UFMG. Desse total, foram descartados, segundo os critérios de exclusão estabelecidos, 1304 documentos por não possuírem ligação com a temática, ainda que, em algumas situações, uma ou mais palavras-chave fossem mencionadas nos documentos. Com essa exclusão, restaram 452 documentos. Mais uma vez, houve necessidade de eliminar teses e dissertações que tratavam da temática de maneira indireta, ou seja, sem inclui-la no escopo das pesquisas, o que reduziu a quantidade final de documentos para 45 entre teses e dissertações.

O total absoluto de recuperações realizadas por todas as palavras-chave foi de 80 , sendo as principais distribuídas conforme o Gráfico 1.

Gráfico 1 - Percentual de recuperações das palavras-chave PPG/UFMG de 2000 a 2016

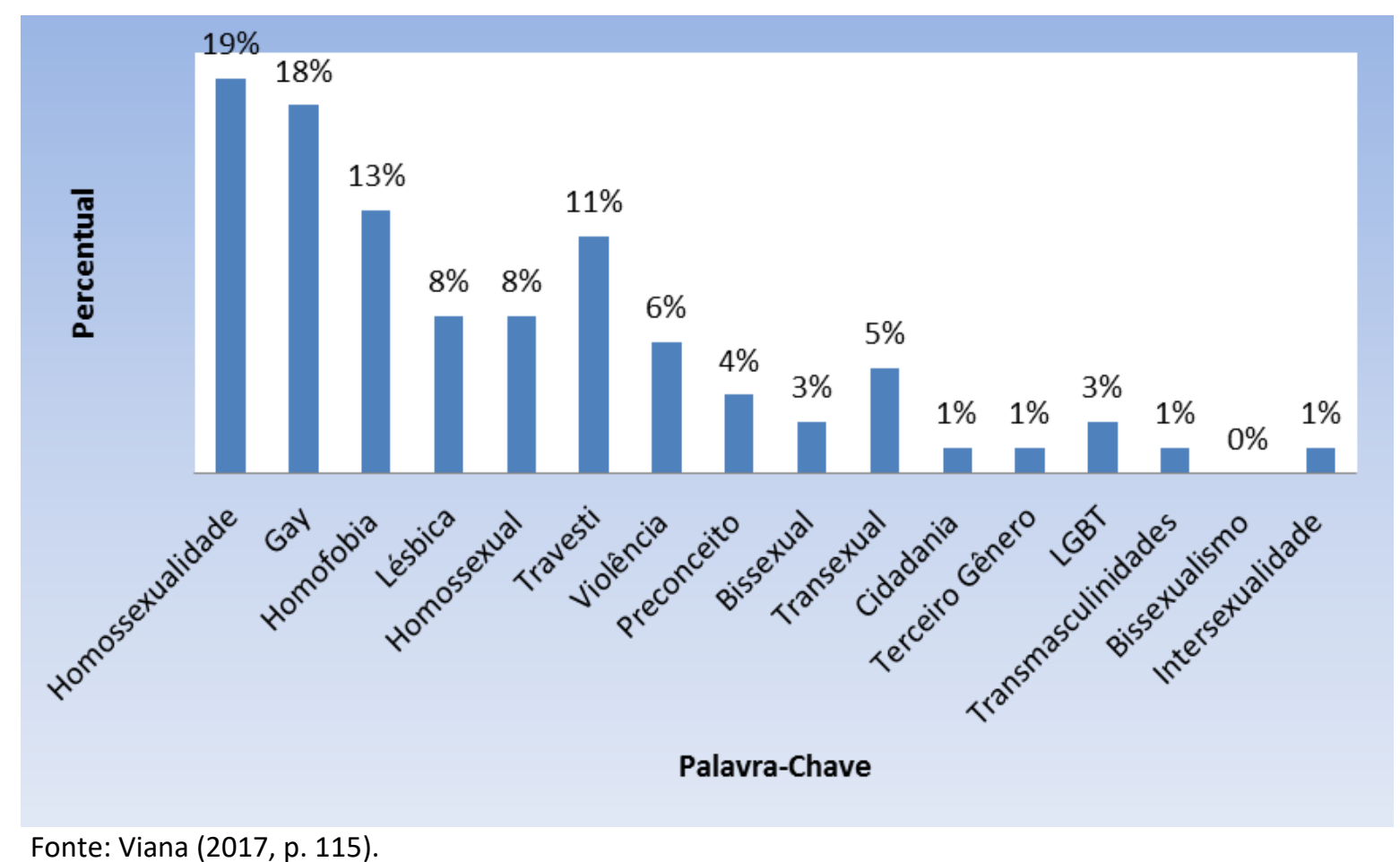

Fonte: Viana (2017, p. 115).

O termo homossexualidade foi responsável pela recuperação de $19 \%$, isto é, pela recuperação da maior quantidade de documentos, 15 no total. A utilização do termo homos-

${ }^{5}$ A palavra documento será utilizada para referir-se, neste estudo, a teses e dissertações. 
sexualidade demonstra que a universidade começa a refletir, investigar, pesquisar a temática sob o prisma da sexualidade humana. A utilização desse termo constituiu-se como elemento afirmativo depois que a Organização Mundial de Saúde (OMS), em 1990, retirou da Classificação Internacional de Doenças (CID 10) ${ }^{6}$ a palavra homossexualismo, substituindo-a por homossexualidade, uma vez que o sufixo "ismo" possui conotação ligada à doença. O novo termo refere-se a um aspecto da sexualidade humana e apresenta elemento semântico positivo.

Já o termo homossexual foi responsável por $8 \%$ do total. Ainda que de mesma origem etimológica de homossexualidade, esse termo se refere a comportamento ou relacionamento entre as pessoas. Por isso, optou-se por utilizar as duas palavras, tendo em vista que possuem aplicação diferente uma da outra. Tal opção permitiu recuperar documentos diferentes, pois enquanto alguns PPG investigam as relações da sexualidade humana, outros pesquisam os sujeitos/usuários a partir da expressão de sua afetividade (sexualidade).

Na verificação realizada, os assuntos "homofobia", "preconceito" e "violência" apareceram de maneira recorrente, o que sugere que a questão da violência é ainda muito presente no cotidiano desse segmento, o que impactou diretamente as pesquisas desenvolvidas. Merece destaque a utilização de novas terminologias e novas discussões, como, por exemplo, as palavras-chave "transmasculinidades", "intersexualidade", "terceiro gênero". No momento em que as buscas com as palavras-chave foram realizadas, ao utilizar apenas a expressão "trans", houve a recuperação do termo "transmasculinidades". O mesmo ocorreu com as palavras "gênero" e "sexualidade".

Percebeu-se que, em algumas situações, as novas terminologias foram empregadas para explicitar novos desdobramentos semânticos, seja nas discussões em torno de orientação sexual e identidade de gênero, como é o caso das palavras-chave "intersexualidade" e "transmasculinidades", cujo aparecimento é recente e encontram respaldo na obra de Judith Butler ${ }^{7}$, que defende a desconstrução da rigidez, tanto do gênero quanto de suas identidades.

Os termos vinculados à orientação sexual e de identidade de gênero compõem o grupo de relevância por concentrar grande parte das investigações mapeadas e evidenciadas no Gráfico 1, apresentado anteriormente.

A análise foi realizada separando-se em dois períodos temporais compreendidos de 2000 a 2009 e de 2010 a 2016, respectivamente, tanto para as teses quanto para as dissertações, conforme demonstrado no Gráfico 2.

Em relação às dissertações, houve um aumento de $146 \%$ do total absoluto produzido de 2000 a 2009 para o período de 2010 a 2016. Isto é, na primeira década, foram encontradas 13 dissertações. Na segunda década, esse número foi de 19 dissertações. Já em relação às teses, esse aumento foi de $225 \%$ do total absoluto produzido de 2000 a 2009 para o produzido de 2010 a 2016, ou seja, na primeira década, foram recuperadas quatro teses. O total de recuperações da segunda década foi de nove teses.

\footnotetext{
${ }^{6}$ A Classificação Estatística Internacional de Doenças e Problemas Relacionados com a Saúde, frequentemente designada pela sigla CID (em inglês: International Statistical Classification of Diseases and Related Health Problems - ICD), fornece códigos relativos à classificação de doenças e de uma grande variedade de sinais, sintomas, aspectos anormais, queixas, circunstâncias sociais e causas externas para ferimentos ou doenças. Disponível em: http://www.cid10.com.br/. Acesso em: 15 abr. 2020.

${ }^{7} J u d i t h$ Butler é filósofa e autora da teoria denominada de teoria queer. Essa teoria se alicerça na problematização da identidade enquanto aspecto provisório e em constante reconstrução. Seu pensamento foi influenciado por Michel Foucault e pelos filósofos pós-estruturalistas, principalmente os franceses (ROCHA, 2014).
} 
Gráfico 2 - teses e dissertações defendidas nos PPG/UFMG de 2000 a 2016

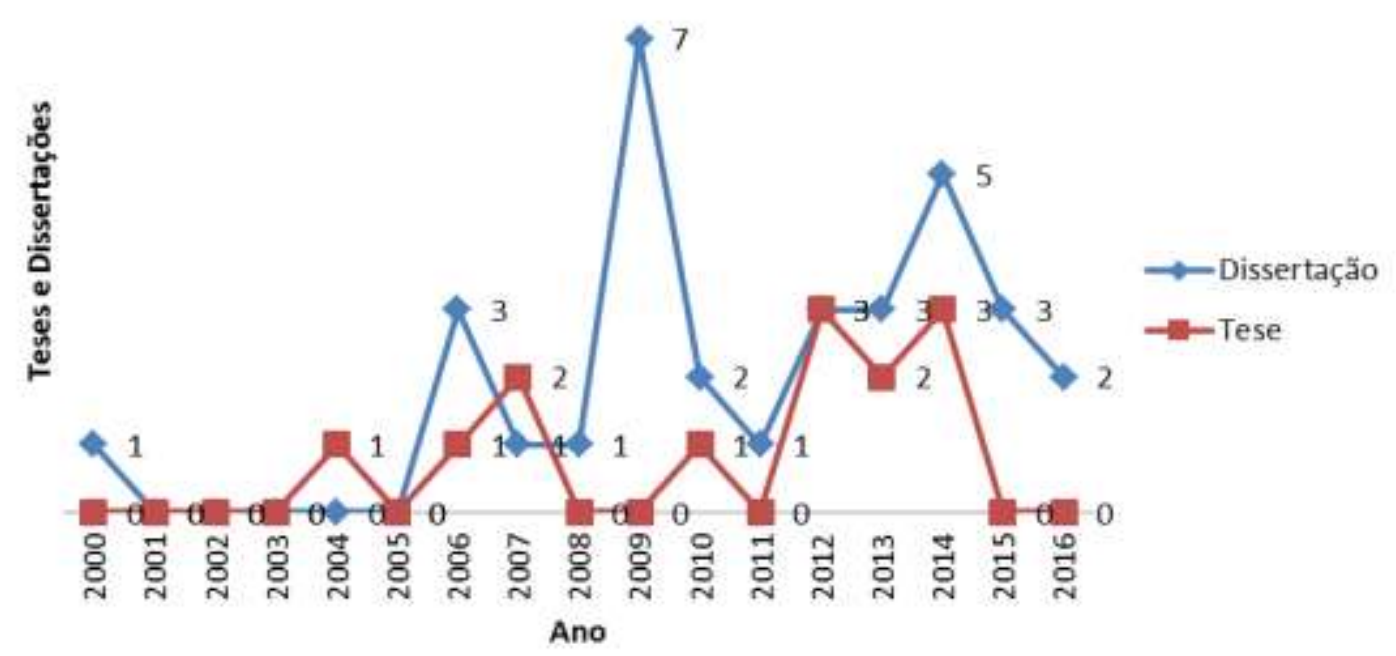

Fonte: Viana (2017, p. 93).

Essa constatação pode estar vinculada à mudança na gestão pública federal a partir de $2003^{8}$. Entende-se que houve uma valorização de pesquisas em diversas áreas do conhecimento, o que pode ter contribuído para o desenvolvimento de investigações e levantamentos de problemas voltados para as demandas do segmento LGBT. Assim, como consequência, a efetivação e obtenção de dados e informações que permitiu haver certa repercussão social dos temas inerentes à temática na produção científica na UFMG.

\subsection{Evidenciações da temática Biblioteca Pública}

A análise da produção científica revelou os números e a proporção das pesquisas de acordo com a tipologia; a distribuição dessa produção entre os PPGCl; distribuição temporal e os termos recorrentes.

Foram recuperadas 88 pesquisas, sendo 73 (83\%) teses e 15 (17\%) dissertações, defendidas nos PPGCI. Uma das razões que explica um predomínio maior de dissertações é o fato de que o primeiro curso de doutorado em Ciência da Informação foi implantado no Brasil na década de 1990. Além disso, a UFPE, a UEL, a UNIRIO e a UDESC, até a data dessa pesquisa, ainda não possuíam curso de doutorado.

O Gráfico 3 demonstra a quantidade de teses e dissertações defendidas nos PPGCI, representados por suas respectivas instituições de ensino.

A temática Biblioteca Pública foi mais presente nos PPGCI da UFPB, com 19 publicações, e da UFMG, com 18 publicações. Diante desse resultado, pode-se inferir que os números refletem a importância dada ao tema nesses programas. Evidencia-se que tais programas já iniciaram com áreas de concentração e linhas de pesquisas voltadas para o planejamento e gerência de Bibliotecas Públicas; o estudo das relações entre biblioteca, sociedade e educação; a promoção do hábito da leitura e ao acesso à informação para a cidadania.

\footnotetext{
${ }^{8}$ A vitória do Partido dos Trabalhadores com a eleição de Luiz Inácio Lula da Silva para a Presidência da República iniciou um processo de desenvolvimento de políticas públicas voltadas para o segmento LGBT que se consolidou com o lançamento do programa Brasil sem homofobia. Esse programa foi constituído por um conjunto de ações afirmativas voltadas para as pessoas LGBT com participação de 10 ministérios, com vistas a combater o preconceito e garantir direitos a esse segmento.
} 
Gráfico 3 - Teses e dissertações defendidas nos PPGCI de 1970 a 2015

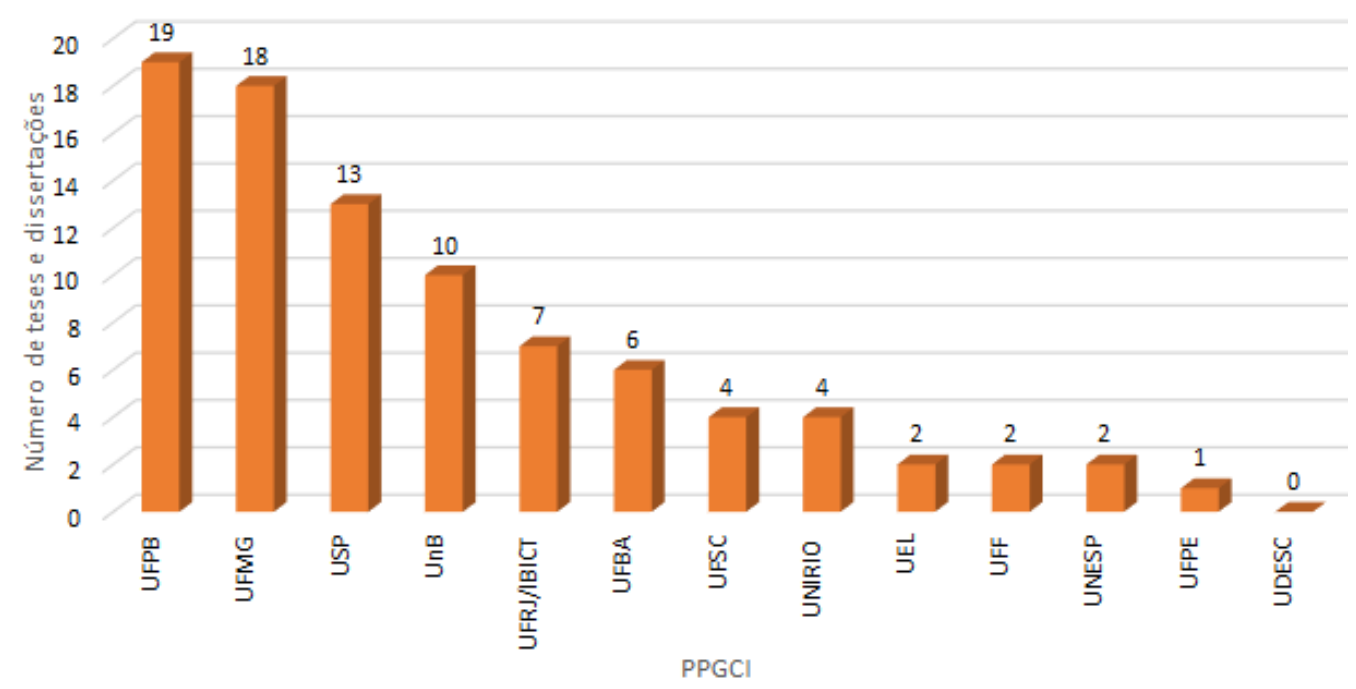

Fonte: Ferreira (2017, p. 97).

Em seguida, aparece a USP, com 13 publicações. Pode ter contribuído para esse resultado a atuação de professores e pesquisadores sobre Biblioteca Pública. O primeiro deles seria Luiz Augusto Milanesi ${ }^{9}$, autor de tese, livros e artigos sobre a temática. Além das reflexões teóricas, o autor também trouxe para a área e para o PPGCI/USP suas vivências práticas como Diretor Técnico na Divisão de Biblioteconomia do Departamento de Atividades Regionais da Cultura junto à Secretaria Estadual da Cultura de São Paulo. O segundo, Oswaldo Francisco de Almeida Júnior ${ }^{10}$, professor, pesquisador e autor de dissertação e tese sobre Biblioteca Pública, pela USP, além de artigos e livros sobre a temática.

A UnB aparece com 10 publicações. Infere-se que a temática tenha ganhado maior atenção devido à existência da linha de pesquisa "Comunicação e Mediação da Informação", na qual está localizado o grupo de pesquisa "Biblioteca e Sociedade ${ }^{11 "}$ ". Esse grupo vem estudando a utilização da técnica de segmentação de mercado pelas bibliotecas como um meio de atender às variadas demandas de informação e leitura da comunidade.

Embora o PPGCI da UFRJ seja o mais antigo, apareceu com apenas sete publicações. Esse fato pode ser explicado pela estrutura do programa que, à época de sua criação, refletia a preocupação internacional em capacitar pessoal para lidar com a excessiva produção de informação científica e tecnológica, e tinha como foco os sistemas de armazenamento e recuperação da informação (FERREIRA, 1995).

\footnotetext{
${ }^{9}$ Luiz Augusto Milanesi é professor titular da Escola de Comunicações e Artes, na USP, onde ministra várias disciplinas, dentre elas "Biblioteca, Informação e Sociedade", que tem como um dos objetivos analisar o papel das bibliotecas enquanto instituições articuladas a determinados organismos públicos.

${ }^{10}$ Oswaldo Francisco de Almeida Júnior é professor titular do Programa de Pós-Graduação em Ciência da Informação da Universidade Estadual Paulista Júlio de Mesquita Filho (UNESP/Marília), professor associado da Universidade Estadual de Londrina e professor colaborador do Mestrado Profissional da Universidade Federal do Cariri, no Ceará. Continua trabalhando e pesquisando sobre bibliotecas públicas. Tem como temas de pesquisa: bibliotecas públicas, informação e sociedade, mediação da informação, serviço de referência e informação e Biblioteconomia.

${ }^{11}$ O grupo de pesquisa "Biblioteca e Sociedade" foi criado na Universidade de Brasília em 2006 e encontra-se ativo em 2020. A concepção de segmentação de mercado baseia-se em abandonar a ideia de a biblioteca pública ser tudo para todos e segmentar um setor da comunidade. Tem como líderes os professores e pesquisadores Emir José Suaiden e Kira Tarapanoff.
} 
Em seguida, aparecem: a UFBA, com seis publicações; a UFSC e a UNIRIO com quatro publicações cada uma. A UNESP, UFF e a UEL tiveram duas publicações cada uma e a UFPE teve apenas uma publicação. Há que se ponderar que esses PPGCl tiveram início a partir do ano de 1998, o que pode ter contribuído para o parco número de teses e dissertações.

A UDESC foi a única em que não houve nenhum trabalho defendido sobre Biblioteca Pública. Considerando que o curso iniciou em 2013 e que as primeiras dissertações foram defendidas em 2015 (data limite dessa pesquisa), não se pode inferir e tampouco afirmar que esse tema não seja de interesse do Programa.

O Gráfico 4 demonstra a distribuição, por década, das teses e dissertações. Os períodos que tiveram mais pesquisas sobre biblioteca pública foram 2010 a 2015, totalizando 35 $(39,8 \%)$ produções, e 1980 a 1989, com 23 (26,1\%) produções. Os mesmos foram seguidos pelos períodos de 2000 a 2009, com 15 produções (17\%) e o de 1990 a 1999, com 14 (15,9\%). Na década de 1970, houve apenas uma (1,1\%) dissertação defendida sobre Biblioteca Pública, a pesquisa realizada pelo Professor Emir José Suaiden.

Gráfico 4 - Teses e dissertações defendidas de 1970 a 2015 apresentadas por décadas

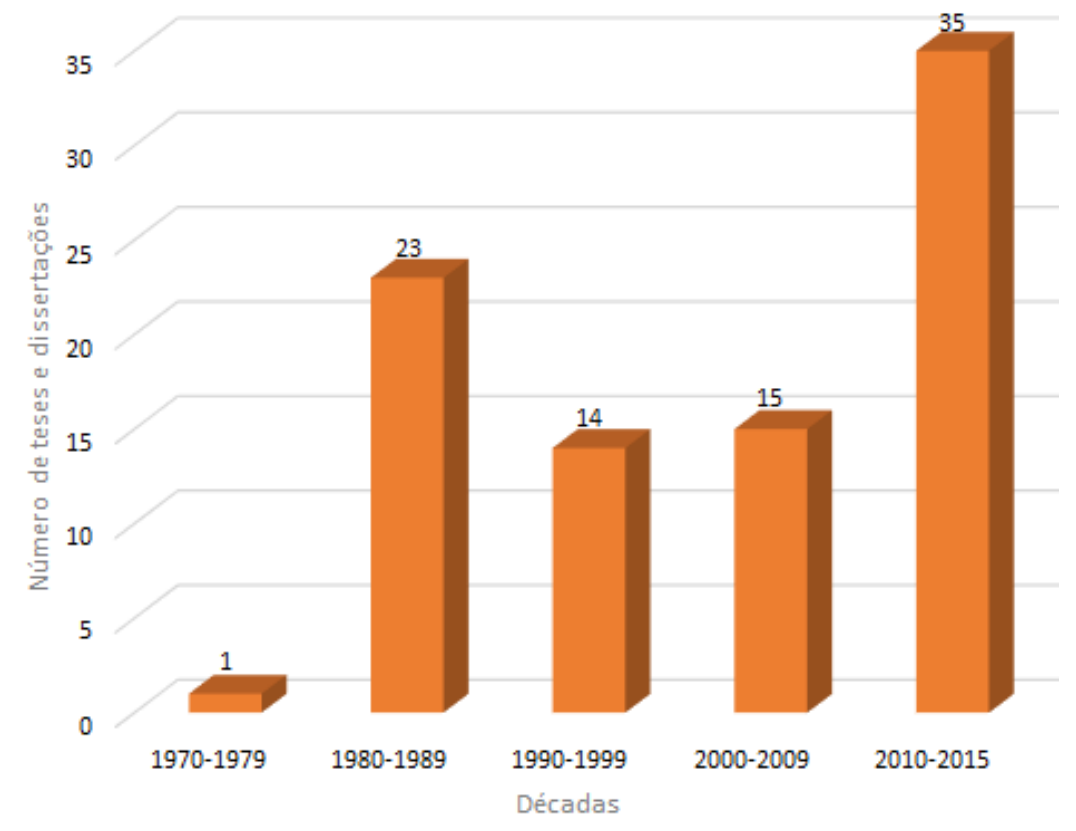

Fonte: Ferreira (2017, p. 94).

A década de 1980 foi, no contexto nacional, um período de muitas discussões sobre democracia, dos grandes movimentos sociais e populares em busca dos direitos de acesso aos serviços públicos bem como de sua importância e valorização. Incluem-se nesse período a mobilização nacional contra o regime militar envolvendo partidos políticos, sindicatos, movimentos populares; o movimento das Diretas Já, em 1984, mobilização nacional de reivindicações por eleição direta para presidência da República; e o movimento nacional próConstituinte, 1985 a 1989, que reivindicava a elaboração de uma nova Constituição com a participação do povo brasileiro (GOHN, 1997). Depreende-se que foi fundamental o papel das universidades para as discussões e reflexões sobre os problemas sociais da época, inclusive, sobre aqueles em que as bibliotecas exerceriam a função primordial de dar acesso democrático à informação e à cultura. 
A temática teve maior evidência a partir de 2010, quando houve um aumento significativo de pesquisas sobre Biblioteca Pública, especialmente em 2011, com cinco dissertações; nos anos de 2013 e 2014, com cinco dissertações e duas teses, em cada; e no ano de 2015, apresentando nove dissertações e duas teses.

O aumento do comprometimento público e da sociedade civil com a construção de uma política pública para bibliotecas pode ter sido um fator de estímulo à produção científica sobre a temática nesses últimos cinco anos. Algumas iniciativas ganharam destaque, tais como: a aprovação do Plano Nacional do Livro e da Leitura, instituído por meio da Portaria Interministerial do Ministério da Educação (MEC)/Ministério da Cultura (MinC) no 1.442, em 2006, e do Decreto no 7.559, de 2011, que o institucionalizou; o Projeto de Lei no 3.727, de 2012, que dispõe sobre o princípio da universalização das Bibliotecas Públicas no País; os diversos Planos do Livro, Leitura, Literatura e Bibliotecas que vêm sendo criados em âmbitos estadual e municipal, como os PMLLB de Salvador/Bahia(BA) e São Paulo/SP, dentre outros.

Para analisar a ocorrência dos termos usados pelos autores para representar o conteúdo de suas pesquisas, consideraram-se as palavras-chave identificadas nas teses e dissertações. Para as publicações sem esse recurso, optou-se por utilizar os termos empregados para indexá-las nas bases de dados pesquisadas.

Considerando que foram variadas as fontes de pesquisa, é de se prever que também fossem variados os termos (cerca de 290) e as regras utilizadas para descrever essas publicações, conforme é mostrado no Gráfico 5.

Gráfico 5- Termos mais utilizados para representar os conteúdos das teses e dissertações

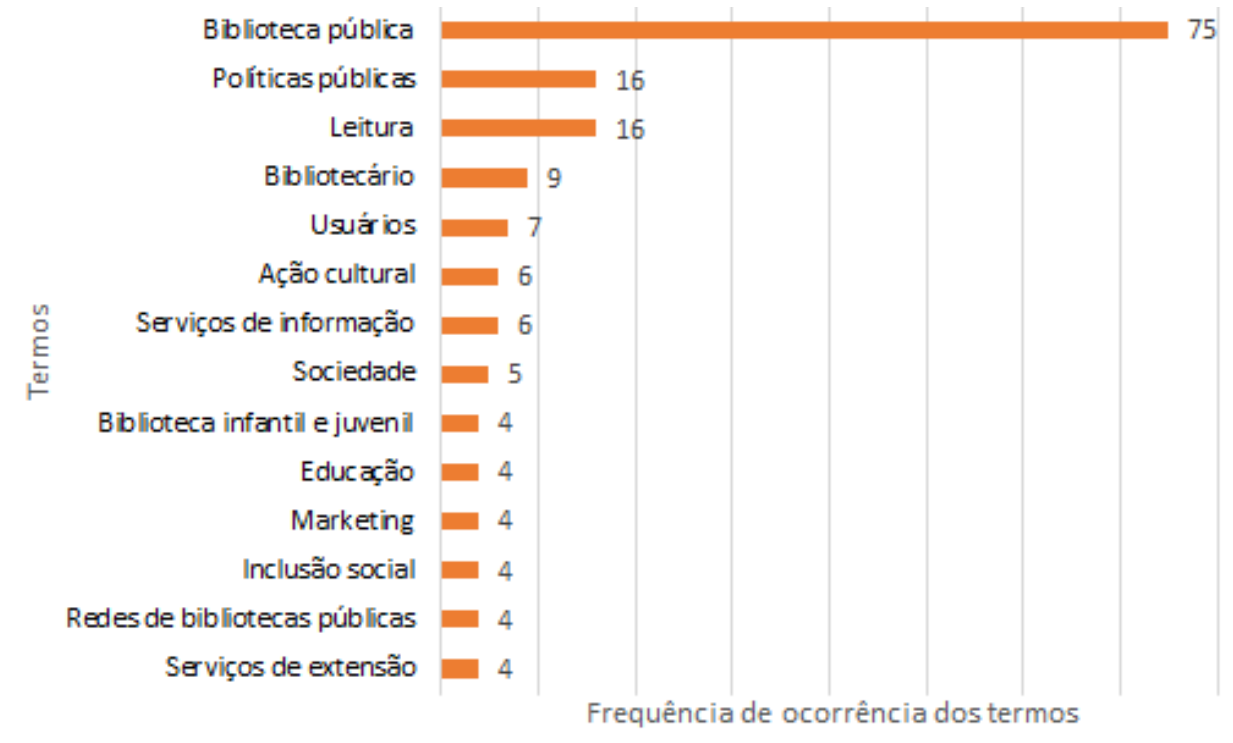

Fonte: Ferreira (2017, p. 103).

O recorte permitiu identificar 14 termos e, como esperado, a temática da Biblioteca Pública foi o que teve mais incidência nas pesquisas: 75 vezes. Em seguida, os termos leitura e políticas públicas aparecem 16 vezes cada um; o termo bibliotecário apareceu nove vezes; o termo usuários apareceu sete vezes; serviços de informação e ação cultural apareceram seis vezes cada um; sociedade apareceu cinco vezes.

Os termos serviço de extensão, redes de bibliotecas públicas, inclusão social, marketing, educação e biblioteca infantil e juvenil apareceram quatro vezes cada um. Pela análise 
desse gráfico, é possível verificar a preferência (ou a necessidade) dos pesquisadores em estudar a Biblioteca Pública mais sob o foco das políticas, das atividades culturais e dos serviços prestados à comunidade, e menos sob o foco do trabalho técnico.

\section{CONSIDERAÇÕES FINAIS}

As duas pesquisas que embasaram o presente artigo evidenciam o caráter plural e diverso da ciência. Neste estudo, destaca-se que a relevância foi dada ao entendimento que se tem sobre estudos acerca de temáticas sociais, que também perpassam aos métodos e domínios do campo da Ciência da Informação.

No que se refere às conclusões relativas à temática LGBT, a inserção das questões atinentes à orientação sexual e identidade de gênero merece destaque porque revelam a importância da identificação e reconhecimento de lésbicas, gays, bissexuais, travestis e transexuais, além de demonstrar a produção evidenciada.

Foi demonstrado que assuntos ligados à orientação sexual e identidade de gênero ganharam projeção e importância nos PPG o que suscitou novas indagações e suas respectivas inferências, conjecturas e, em alguma medida, respostas a partir das investigações realizadas.

A diversidade de assuntos encontrados, a partir das palavras-chave utilizadas neste estudo, no âmbito da temática LGBT, indica que os aspectos vivenciados pelos cidadãos LGBT encontram respaldo e acolhida entre pesquisadores de departamentos diversos, o que indica importante contribuição para o desenvolvimento de novos assuntos e temáticas.

$O$ recorte temporal indicou haver uma produção científica no que se refere à temática LGBT, em consolidação nos PPG da UFMG.

No que diz respeito às conclusões relativas à temática sobre a Biblioteca Pública, a pesquisa revelou que, tendo em vista o período de 45 anos estudados, o número de teses e dissertações sobre o assunto, produzidas no âmbito de 13 PPGCl no Brasil, foi muito parcimonioso. Entretanto, revelou também que é um tema que está, sim, inserido nas agendas de pesquisas, ainda que de forma descontínua. Entende-se que a temática não tem merecido o tratamento necessário nas agendas de pesquisa na pós-graduação brasileira em Ciência da Informação.

Isso pode ser percebido na distribuição temporal dessas pesquisas, no caso da temática sobre a Biblioteca Pública, dando destaque para as décadas de 1980 e de 2000, cujo gráfico demonstrou serem essas as décadas com mais produções. Períodos esses em que houve, respectivamente, uma mobilização nacional em prol de um país democrático e o comprometimento com a construção de uma política pública para bibliotecas, podendo esses motivos terem levado, assim, ao estímulo dos estudos sobre o tema.

Trazer a Biblioteca Pública à tona significa reconhecer sua contribuição para o desenvolvimento local e seu papel como agente de transformação social. Compreende-se que, a partir do momento que ela promove o acesso democrático ao livro, à leitura e à cultura, contribui para a formação de cidadãos mais bem informados, críticos e autônomos.

Isso posto, pode-se afirmar que as duas temáticas encontram-se inseridas nas agendas de pesquisa dos PPG, o que valida a importância da comunicação e disseminação dos resultados, tanto para o desenvolvimento de novas temáticas quanto sua consolidação em campos e áreas do conhecimento. Observa-se ainda que a Ciência da Informação tem sido uma área que acolhe pesquisas, as mais diversas, distintas e plurais, reforçando o seu caráter intrínseco de interdisciplinaridade conforme entendimento de Saracevic (1995). 


\section{REFERÊNCIAS}

CAMPELLO, B. S. Teses de dissertações. In: CAMPELLO, B. S; CENDÓN, B. V.; KREMER, J. M. (org.) Fontes de informação para pesquisadores e profissionais. Belo Horizonte: Ed. UFMG, 2007. p. 121-128.

CHRISTOVÃO, H. T. Da comunicação informal a comunicação formal: identificação da frente de pesquisa através de filtros de qualidade. Ciência da Informação. Rio de Janeiro, v. 8, n. 1, p. 3-36, 1979. Disponível em: http://revista.ibict.br/ciinf/article/view/135/135. Acesso em: 15 abr. 2020.

CUNHA, M. B. da; CAVALCANTI, C. R. de O. Dicionário de Biblioteconomia e Arquivologia. Brasília: Briquet de Lemos, 2008. p. 97.

FERREIRA, J. R. 25 anos do Programa de Pós-Graduação do IBICT. Ciência da Informação, Brasília, v. 24, n. 1, p. 5-6, jan./abr. 1995. Disponível em:

http://revista.ibict.br/ciinf/article/view/601/603. Acesso em: 15 abr. 2020.

FERREIRA, S. A. Produção Científica sobre Biblioteca Pública nos Programa de PósGraduação em Ciência da Informação no Brasil. 2017. 164 f. Dissertação (Mestrado em Ciência da Informação) - Escola de Ciência da Informação, Universidade Federal de Minas Gerais, Belo Horizonte, 2017.

GOHN, M. G. Teoria dos movimentos sociais: paradigmas clássicos e contemporâneos. São Paulo: Loyola, 1997. 383p.

GARVEY, W. D. Communication, the essence of science: facilitating information exchangeamonglibrarians, scientists, engineers and students. Oxford: Pergamon Press, 1979. $322 \mathrm{p}$.

LOURENÇO, C. de A. Automação de bibliotecas: análise da produção científica via Biblioinfo (1986-1994). In: WITTER, Geraldina Porto. Produção científica. Campinas: Átomo, 1997. p. 25-40.

MACIAS-CHAPULA, C. A. O papel da informetria e da cienciometria e sua perspectiva nacional e internacional. Ciência da Informação, Brasília, v. 27, n. 2, p. 134-140, maio/ago. 1998. Disponível em: http://revista.ibict.br/ciinf/article/view/794/824. Acesso em: 15 abr. 2020.

MEADOWS, A. J. A Comunicação científica. Brasília: Briquet de Lemos, 1999.

MUELLER, S. P. M. Literatura científica, comunicação científica e ciência da informação. In: TOUTAIN, L. M. B. B. (org.). Para entender a Ciência da Informação. Salvador: EDUFBA, 2012. p. 125-144.

PIZZANI, L.; MARTINEZ, C. M.S.; HAYASHI, M. C.P. I. Estudo bibliométrico da produção científica em prematuridade na BVS/Bireme. In: HAYASHI, M. C.P. I.; FARIA, L. I. L. de; HAYASHI, 
C.R.M. (org.). Bibliometria e cientometria: estudos temáticos. São Carlos: Pedro \& João Editores, 2013. p. 169-182.

ROBREDO, J. Filosofia da ciência da informação ou ciência da informação e filosofia? In: TOUTAIN, L. M. B. B. (org.). Para entender a ciência da informação. Salvador: EDUFBA, 2012. p. 35-74.

ROCHA, C. B. A. Um pequeno guia ao pensamento, aos conceitos e à obra de Judith Butler. Cadernos Pagu, Campinas, n. 43, p. 507-516, jul./dez. 2014. Disponível em: http://www.scielo.br/scielo.php?script=sci arttext\&pid=S0104-83332014000200507. Acesso em: 15 abr. 2020.

SANTOS, R. N. M.; KOBASHI, N. Y. Aspectos metodológicos da produção de indicadores em ciência e tecnologia. In: ENCONTRO NACIONAL DE CIÊNCIA DA INFORMAÇÃO, 6. Salvador. Anais [...]. Salvador: CINFORM, 2005. Disponível em: http://www.cinformanteriores.ufba.br/vi anais/docs/RaimundoNonatoSantos.pdf. Acesso em: 15 abr. 2020.

SARACEVIC, T. Interdisciplinarity nature of Information Science. Ciência da Informação, Brasília, v. 24, n. 1, p. 36-41, 1995. Disponível em:

http://revista.ibict.br/ciinf/article/view/608/610. Acesso em: 15 abr. 2020.

SOUZA, E. D. de; OLIVEIRA, D. Análise documentária no grupo Temma: dos indícios às evidências da formação de unidades discursivas. Ciência da Informação, Brasília, v. 36, n. 2, p. 74-84, maio/ago. 2007. Disponível em: http://revista.ibict.br/ciinf/article/view/1178/1341. Acesso em: 15 abr. 2020.

VANTI, N. A. P. Da bibliometria à webometria: uma exploração conceitual dos mecanismos utilizados para medir o registro da informação e a difusão do conhecimento. Ciência da Informação, Brasília, v. 31, n. 2, p. 152-162, maio/ago. 2002. Disponível em: http://revista.ibict.br/ciinf/article/view/970/1007. Acesso em: 15 abr. 2020.

VIANA, A. F. A produção científica acerca da temática LGBT: um estudo propedêutico nas teses e dissertações na UFMG. 2017. 145 f. Dissertação (Mestrado em Ciência da Informação) - Escola de Ciência da Informação, Universidade Federal de Minas Gerais, Belo Horizonte, 2017.

WEITZEL, S. da R. Fluxo da informação científica. In: POBLACION, D. A.; WITTER, G. P.; SILVA, J. F. M. da (org.). Comunicação e produção científica: contexto, indicadores, avaliação. São Paulo: Angellara, 2006. p. 81-114.

WITTER, G. P. Introdução. In: PONTIFÍCIA UNIVERSIDADE CATÓLICA DE CAMPINAS. Catálogo de publicações dos docentes 1990/1994. Campinas, 1996.

ZIMAN, J. Conhecimento público. Belo Horizonte: Itatiaia, 1979. 164 p.

ZIMAN, J. A força do conhecimento: a dimensão científica da sociedade. Belo Horizonte: Itatiaia, 1981. 380p. 